\title{
Wet Age Related Macular Degeneration
}

\author{
Fardad Afshari, Chris Jacobs, James Fawcett and Keith Martin \\ University of Cambridge, \\ UK
}

\section{Introduction}

Age related macular degeneration (AMD) is the leading cause of blindness in the developed countries. Approximately 8 million people in America have AMD and the number of advanced AMD is likely to rise by $50 \%$ by year 2020 due to the projected increase in the number of elderly people (Friedman et al., 2004). AMD is a condition of significant morbidity in terms of both physical and mental health (Hassell et al 2006). The burden of this disease is multifaceted as both the individual and society bear a cost. The individual has a loss of independence and ability of self care, with a pressure on society to fulfil the need for community and vision related support.

In this review of AMD, we will explore the epidemiology of AMD, the criteria for diagnosis with particular focus on the pathophysiology and treatments of wet AMD.

\subsection{Epidemiology}

AMD affects a large proportion of the elderly population. By applying the criteria of presence of macular drusen greater than 63 micrometres in diameter on fundus photography, up to $61 \%$ of adults over 60 years have some degree of AMD (Piermarocchi et al 2011). With a high estimated prevalence, it is important to understand the potential risk factors for this condition.

A meta analysis of published data suggests that increasing age, current cigarette smoking, previous cataract surgery, and a family history of AMD show strong and consistent associations with late AMD. Risk factors with moderate and consistent associations were higher body mass index, history of cardiovascular disease, hypertension, and higher plasma fibrinogen. Risk factors with weaker and inconsistent associations were gender, ethnicity, diabetes, iris colour, history of cerebrovascular disease, and serum total and HDL cholesterol and triglyceride levels (Chakravarthy et al 2010).

Direct associations between AMD and age, cataract, family history, alcohol consumption, the apolipoproteins A1 and B were also found in a 14 year follow up amongst a city populations (Buch et al 2005). In addition, recent data on human genome project have linked a complement $\mathrm{H}$ polymorphism Try402His on chromosome 1 to increased risk of AMD (Klein et al.,2005). Ala69ser polymorphism in the ARMS2 gene on chromosome 10 is yet another instance where genetic susceptibility for this condition has been established (Rivera et al., 2005). It has also been shown that ARMS2 polymorphism together with smoking, can 
synergistically increase the risk of developing AMD (Schmidt et al., 2006). Therefore it is evident that AMD is a result of interplay of genetic and environmental factors leading to the final pathology.

Better understanding of risk factors can help to identify individuals at high risk for wet AMD who may benefit from early intervention with existing or novel therapies. Using visual acuity as an outcome measure, visual prognosis is more favourable in patients with early intervention (Wong et al 2008).

\subsection{Classification of AMD and diagnosis}

AMD is characterized by the deposition of polymorphous material between the retinal pigmented epithelium and Bruch's membrane (Jager et al., 2008). These depositions are named Drusen. Drusen are categorised by sizes as, small $(<63 \mu \mathrm{m})$, medium $(63-124 \mu \mathrm{m})$ and large $(>124 \mu \mathrm{m})$ (Bird et al., 1995). They are also considered as hard or soft depending on the appearance of their margins on opthalmological examination. While hard drusens have clearly defined margins, soft ones have less defined and fluid margins (Bird et al., 1995).

Classically the condition is divided in to two main subtypes; dry/non exudative and wet/exudative. The Age-related Eye Disease Study (AREDS) fundus photographic severity scale is one of the main classification systems used for this condition (Sallo et al 2009):

\section{No AMD (AREDS category 1)}

No or a few small ( $<63$ micrometres in diameter) drusen.

\section{Early AMD (AREDS category 2)}

Many small drusen or a few intermediate-sized (63-124 micrometres in diameter) drusen, or macular pigmentary changes.

\section{Intermediate AMD (AREDS category 3)}

Extensive intermediate drusen or at least one large ( $\geq 125$ micrometres) drusen, or geographic atrophy not involving the foveal centre.

\section{Advanced AMD (AREDS category 4)}

Geographic atrophy involving the foveal centre (atrophic, or dry AMD)

Choroidal neovascularisation (wet AMD) or evidence for neovascular maculopathy (subretinal haemorrhage, serous retinal or retinal pigment epithelium detachments, lipid exudates, or fibrovascular scar).

Wet AMD results from the abnormal growth of blood vessels from the choriocapillaris (choroidal neovascularisation), through Bruch's membrane. The fragility of the blood vessels and inflammatory processes lead to subretinal haemorrhages and fibrovascular scarring. This process can occur de novo or as a progression of dry AMD.

As with many classification systems, there is variability in AMD grading between clinicians. Therefore although such scales are important for accurate follow up of AMD progression, care is needed in their interpretation. 
To classify AMD, multiple ophthalmological tools have proven to be useful including dilated indirect ophthalmoscopy, stereoscopic fundus photography, amsler grid testing, fundus fluorescein angiography (FFA) and optical coherence tomography (OCT). Of the mentioned techniques available, FFA is of great importance as it allows differentiation between neovascularisation attributable to AMD and that caused by other conditions. The use of FFA has enabled sub-classification of wet AMD according to the appearance of the lesions and the location of choroidal neovascularisation in relation to the fovea. The appearance can be described as classic or occult, which is according to the defined features of the membrane at early and late phases. The location can be extrafoveal (choroidal neovascularisation greater than $200 \mathrm{um}$ from the foveal avascular zone), juxtafoveal (choriodal neovascularisation is closer than 200um from the fovealavascualr zone) and sub-foveal (originating or extension of choroidal neovascularisation to the centre of the avascular zone). OCT provides a cross sectional image of the macula and identifies retinal pigment detachment, fluid accumulation and vitero-macular attachments. OCT has become an important tool in the monitoring progression of wet AMD especially in light of new therapeutic possibilities.

\section{Pathophysiology of wet AMD}

In this section we will explore the clinical presentation and the current pathophysiological mechanism underlying the development of AMD.

\subsection{Clinical presentation of wet AMD}

Clinically, AMD presents with visual loss of varying severity. Early in the course of disease, patients can present with very mild symptoms or be completely asymptomatic. Some patients, however, do experience a loss of contrast sensitivity, blurred vision and scotomas as the disease progresses to the intermediate stage (Jager et al., 2008). Other visual abnormalities associated with AMD include metamophopsia(distortion of straight lines), disparity of image size, macropisa and micropsia, hyperopic refractive shift with associated anisometriopia, light glare, floaters, photopsia (Schmidt-Erfurth et al 2004). However, neovascular or wet AMD, unlike the dry subtype, can have a sudden onset of presentation due to subretinal haemorrhages and exudates leading to retinal detachment and a acute visual loss (Jager et al., 2008). Although wet AMD is only responsible for $15 \%$ of the total AMD, it is responsible for more than $80 \%$ of AMD-related severe visual loss and blindness (Fine et al., 1986).

\subsection{Pathophysiological models for AMD development}

Various theories and models have been proposed to explain the pathophysiology of AMD with multiple factors contributing to the final outcome. Most models proposed focus either on the Bruch's membrane or on the retinal pigmented cells overlying this membrane.

Retinal pigment epithelial (RPE) cells, form a single layer of cells overlying Bruch's membrane with photoreceptors located anterior to RPE layer. RPE cells play a very complex role in preserving photoreceptors and their function. One of their major functions is to remove the shed outer segments of the photoreceptors by phagocytosis (Chang and Finnemann, 2007;Finnemann and Silverstein, 2001). It has been shown that failure of this process will result in build up of debris between the retinal layer and the Bruch's membrane leading to retinal degeneration (Nandrot et al., 2004). 


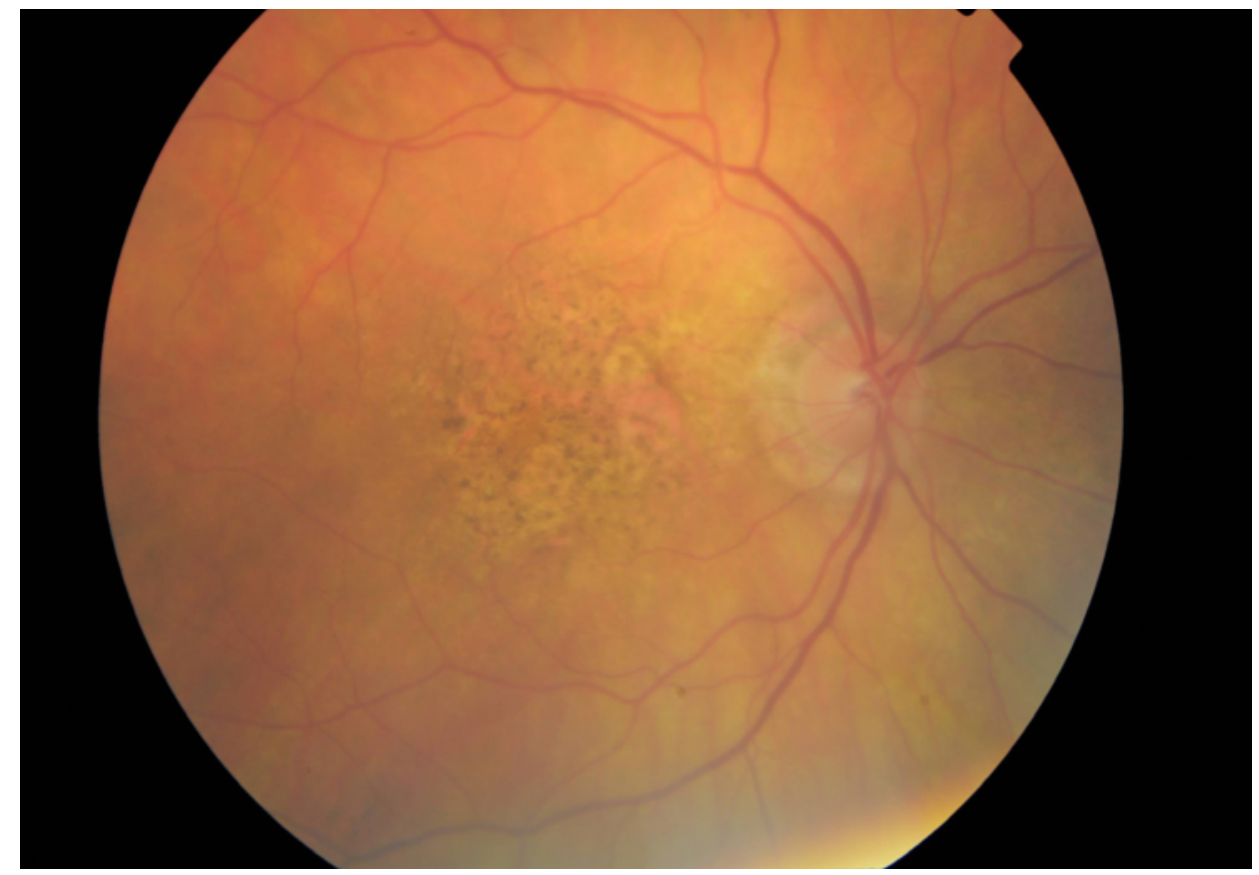

Fig. 1. Fundoscopic view- dry AMD. Note there is no neovascularisation evident.

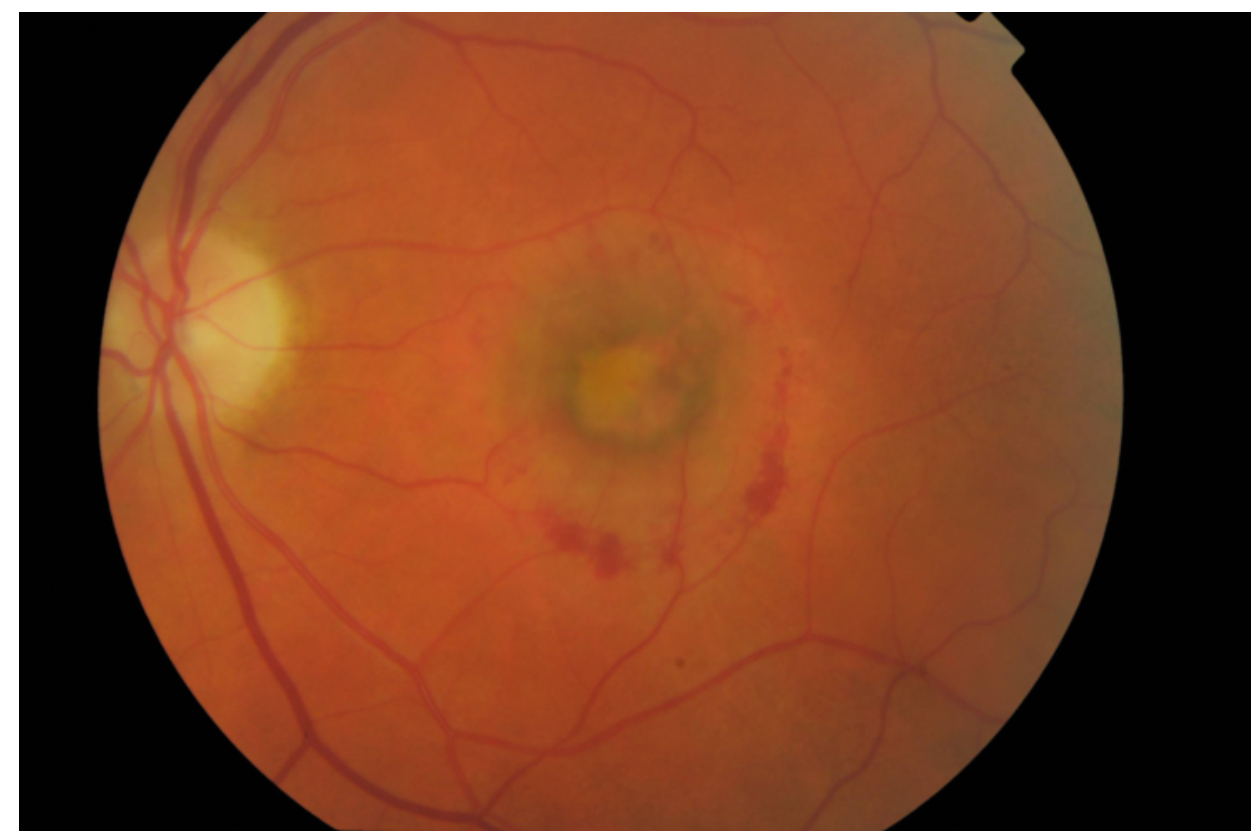

Fig. 2. Fundoscopic view of wet AMD. Excessive neovascularisation in macular region. 


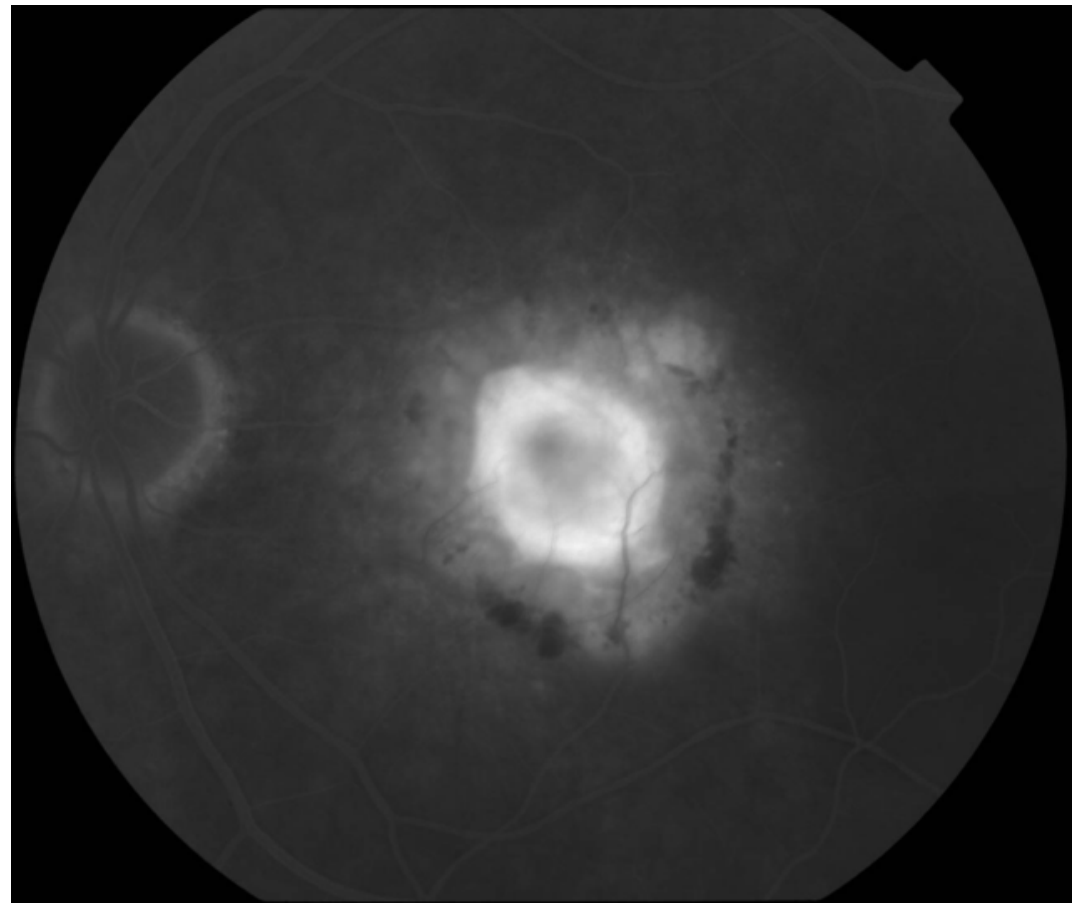

Fig. 3. Fundus fluorescein angiography (FFA) image of corresponding eye affected by wet AMD.

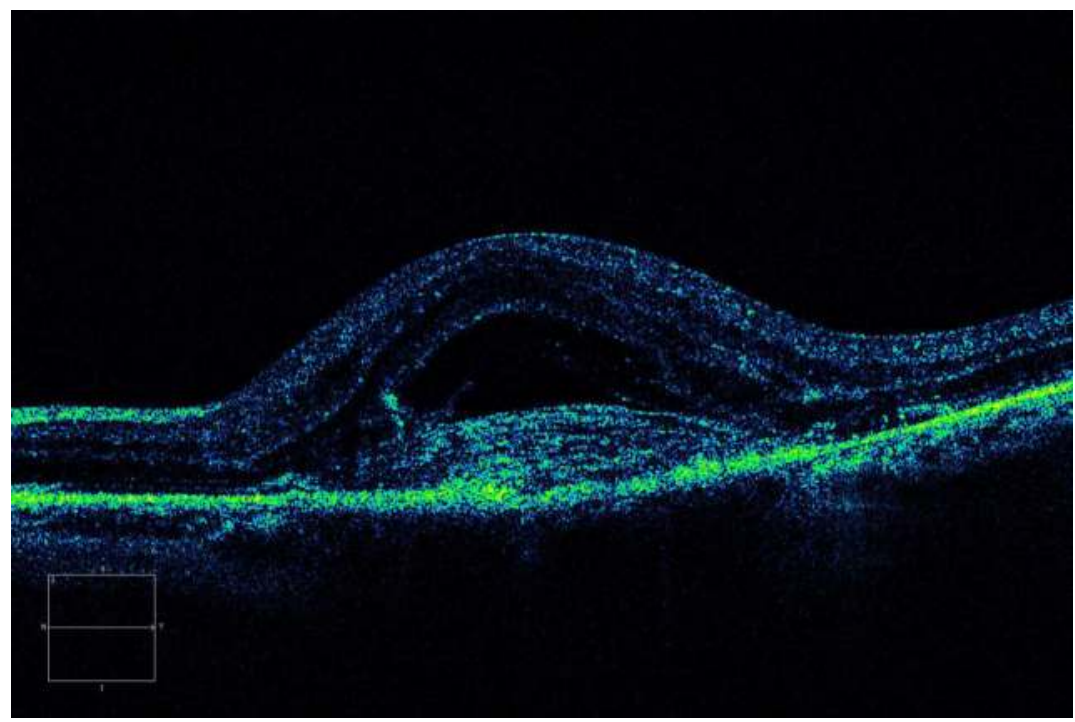

Fig. 4. Optical coherence tomography (OCT) image of corresponding eye. Significant macular oedema is evident. 
In AMD, various abnormalities in the Bruch's membrane have been shown to lead to the disruption of RPE function (Sun et al., 2007), and this in turn can lead to the disruption of photoreceptor function and their loss. Therefore, Bruch's membrane has been the focus of great deal of AMD research.

To understand the pathophysiology of AMD, it is necessary to understand the basic normal structure of Bruch's membrane. Bruch's membrane is a penta-laminar structure, composed of RPE basement membrane, inner collagenous layer, elastin lamina, outer collagenous layer and choriocapillary basement membrane (Zarbin et al 2003). Each layer has a different composition of extracellular ligands, capable of interacting with integrins on the RPE cells. The top layer of Bruch's membrane (the RPE basement membrane) is of great importance as it contains an important extracellular matrix called laminin (Das et al., 1990; Zarbin,2003; Pauleikhoff et al., 1990) necessary for RPE adhesion and attachment.

Over the years, molecular analysis of Bruch's membrane has lead to the identification of composition of each layer as summarized in the table below (Das et al., 1990; Zarbin, 2003; Pauleikhoff et al., 1990).

\begin{tabular}{|l|l|}
\hline $\begin{array}{l}\text { Layer 1. Basement membrane } \\
\text { (Immediately underneath RPE layer) }\end{array}$ & $\begin{array}{l}\text { Collagen IV, Collagen V, laminin, Heparan } \\
\text { sulphate }\end{array}$ \\
\hline Layer 2. Inner collagenous layer & $\begin{array}{l}\text { Collagen I, Collagen III, Collagen V, } \\
\text { fibronectin, Chondroitin sulphate, } \\
\text { dermatan sulphate }\end{array}$ \\
\hline Layer 3. Elastic lamina & Elastin, Collagen I, Fibronectin \\
\hline Layer 4. Outer collagenous layer & $\begin{array}{l}\text { Collagen I, Collagen III, Collagen V, } \\
\text { fibronectin, Chondroitin sulphate, } \\
\text { Dermatan sulphate }\end{array}$ \\
\hline $\begin{array}{l}\text { Layer 5. Choriocapillaries basement } \\
\text { membrane }\end{array}$ & $\begin{array}{l}\text { Collagen IV, Collagen V, Collagen VI, } \\
\text { laminin, heparan sulphate }\end{array}$ \\
\hline
\end{tabular}

Table 1. Matrix components of different layers of Bruch's membrane.

Each layer of Bruch's membrane is composed of mixture of proteoglycans and adhesive ligands. Adhesive ligands interact with integrins on the surface of RPE cells. Different subunits of integrins interact with different class of ligands. RPE cells attachment to Bruch's membrane is largely dependent on integrin's ability to anchor the cell to the membrane firmly. Pathological states affecting the membrane or RPE cells therefore, may disrupt this important interaction leading to loss of adhesion and death of RPE cells.

A large number of hypotheses have existed regarding pathological processes involved in AMD. Overall, the pathological mechanisms proposed in AMD can be divided into 4 categories of inflammation, oxidative stress, abnormal ECM production, formation of CNVs and neovascularisation (Zarbin, 2004). These various components can happen either sequentially or they can occur simultaneously, leading to the final outcome seen in AMD (Zarbin, 2004).

\subsubsection{The inflammation component}

Although drusen formation is one of the hallmarks of AMD, controversy exists as to whether they are directly involved in the pathology of AMD. Drusen can be found in nonAMD patient eyes incidentally associated with aging (Zarbin, 2004). However, others have 
suggested that the accumulation of large numbers of macular drusen is a necessity for the development of geographic atrophy and choroidal neovascularization characteristic of advanced AMD (Harman, 1956; Wallace, 1999).

Biochemical and immunohistological studies suggest drusen consist of immunoglobulins and components of the complement pathway (such as the C5b-C9 complex), acute phase response proteins raised in inflammation (CRP, amyloid $\mathrm{P}$ component and alpha1antitrypsin), proteins that modulate the immune response (such as vitronectin, clusterin, apolipoprotein E, membrane cofactor protein and complement receptor1), major histocompatibility complex class 2 antigens, and HLA-DR and cluster differentiation antigens (Hageman et al., 1999; Johnson et al., 2000; Mullins et al.,2000; Sakaguchi et al., 2002; Zarbin, 2004). In addition, there are cellular components in drusen including RPE membrane debris, lipofuscin, melanin and choroidal dendritic cells (Ishibashi et al., 1986; Killingsworth, 1987; Mullins et al., 2000).

In support of this inflammatory theory, intravitreal injections of corticosteroids reduce the incidence of laser-induced CNVs in non human primates, possibly by reducing inflammation (Ishibashi et al., 1985).

\subsubsection{Oxidative stress}

It has been shown that with increasing age, oxidative damage in RPE cells also increases (Wallace et al., 1998). This is associated with a decrease in levels of antioxidant protective agents such as plasma glutathione, while oxidized glutathione levels increase. Also antioxidant vitamins, such as vitamin $\mathrm{C}$ and $\mathrm{E}$, show a decline with increasing age (Rikans and Moore, 1988; Vandewoude and Vandewoude, 1987).

In support of oxidation stress as one of the factors involved, accumulation of lipofuscin has been observed in aging eyes. Lipofuscins are derivatives of vitamin A metabolites (Katz et al., 1994). It has been shown that in the first decade of life, they only constitute $1 \%$ of the cytoplasmic volume of RPE cells where as this is increased to $19 \%$ of cytoplasmic volume in the elderly (De La Paz and Anderson, 1992; Feeney-Burns et al., 1984).

In vitro studies suggest that RPE lipofuscin is a photo-inducible generator of reactive oxygen species. Lipofuscin granules are continuously exposed to visible light and to high oxygen tension, which causes the production of reactive oxygen species and oxidative damage to RPE cells (Wassell et al., 1999; Winkler et al.,1999; Zarbin, 2004).

RPE lipofuscin accumulation can ultimately lead to the disruption of lysosomal integrity, induce lipid peroxidation, reduce the phagocytic capacity of RPE cells and ultimately lead to loss of RPE cells (Boulton et al., 1993; De La Paz and Anderson, 1992; Sundelin and Nilsson, 2001; Zarbin, 2004).

Consistent with the oxidative stress model, clinical studies on the use of antioxidants has shown that in patients with extensive intermediate drusen, supplementation with antioxidant vitamins and minerals reduces the risk of developing advanced AMD from $28 \%$ to $20 \%$ (Age related eye disease study research group, 2001).

\subsubsection{Abnormal ECM production}

With aging, various changes can happen to the extracellular matrix deposited within the Bruch's membrane. It has been shown that there is a decline of laminin, fibronectin and type 
IV collagen in the aging RPE basement membrane, particularly over the drusen (Pauleikhoff et al., 1999).

There is an age dependent increase in type I collagen within the Bruch's membrane, with an increase in the thickness of the membrane from 2 micrometres at birth, to up to 6 micrometres in the elderly ages (Ramrattan et al., 1994). During aging, the membrane glycosaminglycans in Bruch's membrane increase in size, and there is an increase in the heparan sulphate proteoglycan content of the membrane (Hewitt et al., 1989). Furthermore, glycation end products can accumulate within the Bruch's membrane with aging, trapping other macromolecules (King and Brownlee, 1996; Schmidt et al., 2000).

RPE cells themselves are the source of many of these ECM molecules. Histologically, abnormal extracellular matrix can be found between the RPE cells and the basement membrane (basal laminar deposits) and external to the basement membrane within the collagenous layers of the membrane (basal linear deposits) (Bressler et al., 1994; Green and Enger, 2005). Drusen therefore can be a localized accentuation of these deposits in AMD (Bressler et al., 1994).

The increase in thickness and change in composition of the Bruch's membrane in AMD can lead to a disruption of the exchange of molecules between choriocapillaris and the subretinal space (Starita et al., 1997).

In support of this model, it has been shown that the hydraulic conductivity of the Bruch's membrane falls exponentially with age. Measurements have shown that most of the resistance to water flow lies in the inner collagenous layer of the Bruch's membrane which is possibly due to accumulation of abnormal entrapped material within this plane (Starita et al., 1997). Therefore, the thickened Bruch's membrane in AMD may lead to a diffusion barrier, leading to RPE and retinal dysfunction (Pauleikhoff et al., 1999; Remulla et al., 1995).

\subsubsection{CNV formation}

Multiple factors have been proposed as promoters of new blood vessels formation in wet AMD. Changes in the ECM is one of the abnormalities seen in AMD which can lead to the formation of new blood vessels. The mechanism by which this phenomenon occurs is not completely understood but is likely to be a multifactorial. The risk of CNV in AMD increases with the increase in Drusen. Some drusen components and advanced glycation end products stimulate the production of angiogenic factors ( $\mathrm{Lu}$ et al., 1998; Mousa et al., 1999). The increased thickness of Bruch's membrane can also lead to reductions in choriocapillary blood flow and hypoxia (Remulla et al., 1995). Hypoxia in turn can upregulate genes Ang-1 and Ang-2, with Ang-1 promoting maturation and stabilization of blood vessels, and Ang-2 conferring endothelial cell responsiveness to angiogenic factors (Hanahan, 1997; Maisonpierre et al.,1997). In addition, RPE cells are themselves known to produce angiogenic factors, such as VEGF, (Kim et al., 1999) which can lead to neovascularisation. High concentrations of VEGF and its receptors are found in CNV and RPE cells (Kliffen et al., 1997; Kvanta et al., 1996). Furthermore, anti-VEGF treatments prevent laser induced CNV formation in primate models of AMD (Krzystolik et al., 2002).

It has been shown that overexpression of VEGF in transgenic mice leads to the formation of aberrant choriocapillaries. However, these vessels are not capable of penetrating the intact Bruch's membrane (Schwesinger et al., 2001). Therefore, damage to Bruch's membrane due 
to various factors in combination with the upregulation of VEGF, can synergistically lead to the choriocapillary $\mathrm{CNVs}$ penetrating the membrane and reaching the subretinal space (Schwesinger et al.,2001; Zarbin ,2004).

One of the molecules that has been studied extensively in our lab is a glycoprotein called tenascin C, known to be overexpressed in angiogenesis (Zagzag and Capo, 2002; Zagzaget al., 1996), neovascularisation and wound healing (Maseruka et al., 1997). Tenascin C deposition can occur in the Bruch's membrane in wet AMD on the basal side of RPE cells (Fasler-Kan et al., 2005) and in association with CNVs in the pathological Bruch's membrane (Nicolo et al., 2000). Tenascin C has been shown to prevent adhesion of RPE cells to extracellular matrix (Afshari et al 2010). Therefore accumulation of this molecule associated with CNV formation may play an important role in RPE loss from the Bruch's membrane seen in AMD (Afshari et al 2010).

In summary, different pathological processes during aging and in AMD can lead to modifications in the Bruch's membrane which ultimately becomes a less supportive environment for the RPE adhesion and function.

\section{Experimental models available for studying wet AMD}

\subsection{In vitro and ex vivo models - Advantages vs disadvantages}

In vitro models have allowed development of simplified systems to study processes involved in wet AMD. Most in vitro models have focused on the role of angiogenesis and isolation of Bruch's membrane to assess adhesion and survival of RPE cells.

Tezel and Del priore first described methodology for accessing different layers of Bruch's membrane to allow in vitro assessment of RPE adhesion at different levels of Bruch's membrane. A combination of enzymatic treatment and mechanical techniques were used to expose each layer sequentially starting from the top basal lamina and moving to deeper structures. Using this technique, it was shown that deeper layers of Bruch's membrane are less supportive of RPE attachment (Del priore et al 1998; Tezel TH 1999 FEB; Tezel TH 1999 March). RPE cell adhesion to Bruch's membrane may play a detrimental role both in AMD and following RPE transplantation.

An alternative way of accessing Bruch's membrane used in our lab is the water lysis technique (Afshari et al 2010). In this method, eye globes are dissected out and separated from their muscle attachments. The anterior chamber is then dissected away leaving the posterior chamber and retina and Bruch's-choroid-sclera. Retinal layer is then carefully removed leaving the Bruch's-choroid-sclera trilaminar structure which can be subsequently exposed to water. Exposure to water leads to lysis of endogenous RPE cells. Lysed RPE cells are then flushed away from the surface of Bruch's membrane using a mini water jet. This procedure therefore results in formation of a denuded Bruch's membrane which can allow further experiments such as transplanting exogenous RPE cells to assess adhesion and migration of the transplanted cells (Afshari et al 2010). The advantages of this technique is that minimal treatment of the tissue is required with preservation of natural Bruch's membrane. In addition the preparation of the Bruch's membrane for adhesion and migration assay is a short procedure. Immunostaining of both frozen sections and electron microscopy of the membranes following water treatment have confirmed complete removal 
of endogenous RPE layer therefore creating a suitable environment for transplanting exogenous cells (Afshari et al 2010). However for assessment of adhesion on different layers such as deeper collagen layers of Bruch's membrane, methodology by Tezel and Del priore et al can be used (Del priore et al 1998; Tezel TH 1999 FEB; Tezel TH 1999 March).

Although much has been learned from the use of eyes derived from experimental animals such as rats and rabbits, a major problem faced is the unique human age related changes and AMD related pathological processes that have been hard to recapitulate in animal models. Therefore recent attention has been on use of human derived Bruch's membrane and ex vivo models whereby pathological or normal samples can be used from donors. A great advantage of this technique is that good methodology exists for isolation of layers of Bruch's membrane, and eyes from various stages of the disease can be studied. A disadvantage of using human samples is the difficulty in obtaining high quality tissue before post mortem deterioration occurs.

\subsection{In vivo models - Advantages vs disadvantages}

In vivo animal models have been used widely in studying AMD. Creating animal models specific for AMD has been a difficult task to achieve. One of the older animal models used in AMD research is Royal College of Surgeons rats (RCS rats) where RPE cells are gradually lost over time along with photoreceptors. RCS rats have been used in RPE transplantation experiments widely to assess efficiency of transplanted cells in replacing the lost endogenous RPE cells and preventing photoreceptor loss (Li and Turner 1988). However these rats are a better model for studying retinitis pigmentosa and therefore may differ considerably with regards to pathology from AMD.

Another used animal model comprises of mechanically scratching the RPE layer. This allows creation of focal areas devoid of RPE cells allowing studying various transplantation or pharmacological treatments. Rabbits are used generally in this model (Philips 2003) due to bigger size of the eye globes allowing easier access.

None of the models above recapitulate the neovascularisation seen in wet AMD. However recently more models have emerged which reproduce the neovascularisation process. Some of these models use growth factors such as b-fibroblast growth factor (FGF) or vascular endothelial growth factor (VEGF) to induce the endothelial cells proliferation and migration to promote CNV formation in rats, rabbits and monkeys (Montezumas.R 2009, Edwards A. 2007, Lassota N 2008, Baba T 2010). Over the years different techniques have been used to deliver growth factors ranging from direct injections, lentiviral vectors, cells secreting growth factors or transgenic animals secreting the VEGF (Spilsbury 2000; julien 2008; Okamoto et al1997; Cui et al 2000) .

Newer techniques which can stimulate CNV formation include injection of matrigel subretinally which allows a suitable environment for blood vessels to grow into (Cao J 2010). An alternative to this has been use of polyethylene glycol injections subretinally which leads to activation of complement cascade and generation of VEGF leading to $\mathrm{CNV}$ formation in mouse (Lyzogubov et al 2011).

Multiple transgenic mice lines also have been created which produce CNV through different methods. One of such animal models is use of transgenic mice producing mitogen prokineticin 1 (Hpk1) which specifically stimulates fenestrated endothelial cells. 
Introduction of this mitogen can lead to CNV formation from choriocapillaries (Tanaka $\mathrm{N}$ 2006). By generating transgenic mice expressing Hpk1 in retina, Tanaka et al were able to show that Hpk1 promotes development of CNV with no effect on retinal vasculature. Interestingly, these mice also show increased levels of lipofuscin which is also seen in AMD (Tanaka N 2006).

One of the most interesting examples of transgenic mice used in studying wet AMD is the $\mathrm{ccr} 2 / \mathrm{ccl} 2$ transgenic mice which are unable to recruit macrophages to RPE layer and Bruch's membrane. This leads to accumulation of $\mathrm{C} 5 \mathrm{a}$ and Immunoglobulin $\mathrm{G}$ which in turn leads to stimulation of VEGF production (Ambati 2003; Takeda et al. 2009).

An alternative method of CNV formation is application of laser to generate a focal area of burn within the Bruch's membrane which in turn leads to $\mathrm{CNV}$ formation. This technique over the years has become one of the most standard and widely used techniques in studying wet AMD. Various laser treatments using krypton, argon and diode have all been able to induce CNV formation in mice, rats, pigs and monkeys (Dobi et al 1989; Frank et al 1989;Ryan et al. 1979; Saishin et al 2003). To initiate CNV formation using laser, it is necessary for RPE layer, Bruch's membrane and the underlying choroid to be damaged by the laser to allow penetration and initiation of new blood vessel formation. The laser induced CNV formation is VEGF mediated, as different methods of blocking VEGF using peptides and antibodies in mice, rats and monkeys are all able to block the neovascularisation process (Hua J 2010; Goody RJ 2011).

\section{Treatments available for AMD and their mode of action}

\subsection{Surgical and cellular transplantation/replacement}

Since defects in Bruch's membrane in age related macular degeneration leads to RPE loss, replacement of RPE cells by transplantation has been proposed as a technique to prevent secondary photoreceptor death. In the past two decades, studies in various animal models of retinal degeneration and RPE loss have shown that RPE cell replacement may be a feasible technique to prevent a secondary photoreceptor loss due to RPE damage (Lund et al., 2001).

Li et al in 1988 demonstrated that RPE transplantation in young neonatal and adult rats allows a repopulation of denuded areas on the Bruch's membrane and prevent the photoreceptor degeneration in dystrophic RCS rat models of AMD (Liand Turner, 1988a, b). In separate studies, Castillo et al have shown that transplantation of adult young human RPE cells derived from cadaveric eye samples, into the dystrophic RCS rats can salvage the photoreceptor loss in this model (Castillo et al., 1997).

Furthermore, subretinal transplantation of the RPE cell line ARPE-19, the most widely used adult human RPE cell line, in dystrophic RCS rats can rescue the photoreceptors (Wang et al., 2005). Other animal models, such as rabbit models of RPE damage, showed that mechanical debridement of the Bruch's membrane followed by autologous RPE transplantation leads to the repopulation of debrided Bruch's membrane with preservation of photoreceptors (Phillips et al., 2003).

In humans patients with AMD, the formation of choroidal new vessels is part of the pathology of advanced wet AMD. The removal of CNVs has also been carried out in human 
patients with AMD. This can be followed by autologous transplantation of RPE cells, either harvested from the periphery of the Bruch's membrane which is not affected by the disease process (Binder et al., 2007), or from RPE cells from other donors (Algvere et al.,1994).

Algevere et al at in 1994 assessed the effect of human fetal RPE transplantation in 5 patients with AMD after the removal of CNVs. Human fetal RPE cells survived up to 3 months and covered the denuded areas of the Bruch's membrane (Algvere et al., 1994).

Other studies have also assessed the effect of adult autologous transplantation of RPE cells in AMD. It has been shown that autolgous transplantation following the removal of CNVs is a feasible technique and associated with some visual acuity improvement (Binder et al., 2004).

In 2007 Maclaren et al carried out autologous transplantation of the RPE cells, following submacular CNV excision, and reported viable grafts at 6 months time point and some level of visual function improvement in some patients. However, the complications associated with the surgery remained high (MacLaren et al., 2007).

RPE transplantation has traditionally been carried out as cell suspension but, due to problems with RPE attachment to Bruch's membrane, more recently RPE-choroid sheets have been tried as a means of delivering RPE cells (Treumer et al 2007). In 2011, FalknerRadler et al, carried out a study comparing RPE cell suspension with that of RPE-choroid sheet transplantation. This study showed that anatomical and functional outcome in both cases were comparable with no significant difference between the two techniques in humans (Falkner-RadlerCl 2011).

Despite some improvements gained in the visual function, the results from the $\mathrm{CNV}$ removal combined with RPE transplantation, have not been as successful as those observed with animal models. This may be due to age related changes specific to human AMD which are absent in the animal models used in studying AMD and RPE transplantation.

RPE transplantation as a therapeutic technique faces major limitations, including poor adhesion of RPE cells when transplanted subretinally. Studies have shown that RPE cells require rapid adhesion to avoid apoptosis (Tezel and Del Priore, 1997,1999). Therefore, there is a limited time period after subretinal injection during which RPE cells need to reattach before undergoing cell death.

The lack of adhesion following transplantation is likely to be multifactorial due to the molecular changes resulting from pathological age related changes in the membrane, and other changes contributed by the disturbance of normal architecture of the membrane from the surgery.

Various studies using ex vivo models have demonstrated major differences between RPE and Bruch's membrane in patients from different ages, emphasizing the important role of aging in the pathological process. Studies by Gullapalli et al have shown that aged submacular human Bruch's membrane does not support adhesion, survival and differentiation of fetal RPE cells effectively (Gullapalli et al., 2005). Multiple studies have shown that RPE cell adhesion to the Bruch's membrane is reduced on aged membranes, when compared to the membrane derived from younger donors (Del Priore and Tezel,1998; Tezel et al., 1999).

In addition to changes in adhesion, survival and differentiation, it has been shown that the capacity of RPE cells to phagocytose the shed outer segment of rod photoreceptors is 
reduced when RPE cells are seeded on aged membranes than the young membranes (Sun, et al., 2007).

These functional differences are further backed up by the changes in gene expression between RPE cells cultured on aged and young membranes. It has been shown that the RPE cells seeded on aged membranes up-regulate 12 genes and downregulate 8 genes compared to RPE cells cultured on membranes derived from young donors suggesting the differences between ages are also reflected at gene level (Cai and Del Priore, 2006).

Therefore, it is evident that there is a significant age-dependent decline in the Bruch's membrane's ability to support the RPE cell adhesion and function, and therefore RPE loss and dysfunction in AMD can be at least partially reflective of changes within the membrane. These changes in Bruch's membrane therefore pose an obstacle for the transplanted RPE cells, which require fast attachment and adhesion, to survive post-transplantation.

In addition, data from our lab and others have shown that in wet AMD, there is increased deposition of a glycoprotein associated with neovascularisation. This glycoprotein named tenascin $\mathrm{C}$ is deposited on the upper layer of Bruch's membrane. Using purified tenascin C, we were able to show that human RPE cells lack the necessary integrins to attach to surfaces coated with this glycoprotein and therefore deposition of this molecule in pathological AMD Bruch's membrane further reduces the chance of adhesion. Using in vitro assays we were able to show that if RPE cells are engineered to express a necessary receptor called alpha9beta1 integrin for tenascin $\mathrm{C}$, they are able to attach following transplantation to the wet AMD derived Bruch's membrane where as in the absence of this receptor, control RPE cells were unable to attach to the membrane effectively (Afshari et al 2010).

In addition to changes mentioned above, surgical techniques used in removal of CNVs have been shown to damage the normal architecture of Bruch's membrane. It is well established that surgical removal of CNVs in the wet AMD generally leads to excision of the basement membrane of the Bruch's membrane (Grossniklaus et al., 1994). Tsukahara et al using ex vivo models of aged Bruch's membrane have shown that the resurfacing of the Bruch's membrane is highly dependent on whether the basement membrane is intact or removed. The adhesion of RPE cells was much higher on aged Bruch's membrane if the basement membrane was not damaged and removed (Tsukahara et al., 2002). Therefore, one of the limitations of the $\mathrm{CNV}$ removal procedure is the iatrogenic removal of the laminin rich basement membrane, which reduces the chance of adhesion of RPE cells transplanted subsequently into the subretinal space.

In addition to the removal of the laminin rich basement membrane of Bruch'smembrane, the surgical procedures also lead to the exposure of deeper layers of the Bruch's membrane. Various studies have assessed the adhesion rate and the survival of RPE cells on different layers of the Bruch's membrane. They have revealed that RPE cell reattachment is the highest on the uppermost layers of the Bruch's membrane which include basement membrane. As deeper layers are exposed, this adhesion rate decreases (Del Priore and Tezel, 1998). Thus, following CNV removal, depending on which layer of the Bruch's membrane is exposed, the outcome of adhesion will differ which diminishes the chances of fast and efficient adhesion of the RPE cells following transplantation (Del Priore and Tezel, 1998).

RPE cells are known to attach to the human Bruch's membrane through beta1 integrinmediated interaction, with extracellular ligands such as laminin, fibronectin, vitronectin and 
collagen IV (Ho and DelPriore, 1997). Tezel et al have demonstrated that laminin and fibronectin supported the adhesion of RPE cells best and prevented cellular apoptosis (Tezel and Del Priore,1997). Since the upper most layers of the Bruch's membrane are rich in laminin and fibronectin, removal of basement membrane combined with the exposure of deeper less adhesive substrates, limits adhesion following transplantation.

Therefore, there is a great need for promoting cell adhesion post transplantation to allow resurfacing and seeding of the pathologically and surgically altered membranes. Multiple problems faced with transplantation therefore haves lead to more attention on pharmacological and less invasive techniques to halt the CNV formation.

\subsection{Photodynamic therapy and laser treatment}

Laser photocoagulation is one of the techniques that was developed to treated neovascularisation problem in wet AMD. Since this technique leads to full thickness retinal burns, this can lead to loss of visual acuity if carried out in foveal region and therefore it is reserved for extrafoveal CNVs. In addition, there is a high rate of recurrence of CNVs following treatment with this method (Vedula SS and Krzystolik M 2011). However this technique is effective in reducing the progression of non-subfoveal CNVs compared to observation alone (Virgil 2007; Verdula SS and Krzystolik M 2011).

Photodynamic therapy on the other hand is a technique that works by injecting a photosensitive dye intravenously which preferentially binds to CNVs. On exposure of the eye to laser light, the dye can be activated leading to obliteration of the CNVs. This technique has the advantage of causing minimal trauma to normal choroid and membrane and the overlying retina. It therefore can be used for subfoveal lesions. The disadvantage with this technique is the necessity to repeat this procedure at least multiple times due to high rate of recurrence (TAP 1999;Verdula SS 2011).

\subsection{Anti-VEGF monoclonal antibodies}

One of the most recent approaches in battling wet AMD is the use of anti-VEGF monoclonal antibodies. Vascular endothelial growth factor has been shown to be involved in promoting formation of new blood vessels. The source of VEGF in AMD is believed to be the RPE cells themselves. Multiple studies have demonstrated presence of VEGF in RPE cells and its association with CNVs (Kim et al. 1999; Klifen 1997; Kvanata 1996). Although VEGF is necessary for neovascularisation, animal research shows that in the presence of intact normal Bruch's membrane, blood vessels will not invade the subretinal area and therefore a pathological process must render the membrane permeable to invading growing new blood vessels in AMD setting (Schwesinger 2001). Regardless of this finding, use of blocking agents against VEGF or its receptor holds promise in halting neovascularisation.

Animal studies have shown that blocking VEGF using different approaches can halt the neovascularisation process. Multiple clinical trials have assessed efficacy and safety of antiVEGF monoclonal antibodies which include Bevacizumab, ranibizumab, pegabtanib (Vendula SS and KrzystolikM 2011). A recent systematic review of randomised controlled trials compared recent trials using anti-VEGF in wet AMD. Pegabtanib and Ranibizumab were shown to be both effective in reducing the neovascularisation with improvements in visual acuity and quality of life (Vendula SS and Krzystolik M 2011). There are currently no 
trials comparing these two drugs directly together. Bevacizumab, which also blocks VEGF and is considerably cheaper than its counterparts, has also been used off licence for treating wet AMD although originally it was licensed for colorectal carcinoma (Avery 2006, Emerson 2007). Although multiple studies have shown efficacy of this monoclonal antibody in reducing neovascularisation, the safety profile of this antibody is not as clear as other two (Mitchell P 2011).

\section{Problems and challenges for future}

With increasing aging population, the number of patients with AMD is likely to rise sharply. The projected number of advanced AMD cases is likely to rise by $50 \%$ by year 2020 (Friedman et al 2004). Therefore with increasing incidence of this condition, screening programs may be of value to allow early detection and treatment of this condition. This is of paramount importance as early detection has been shown to be associated with a better outcome and prognosis (Wong et al 2008).

With recent advances in cell transplantation and knowledge of stem cells, it may be possible that stem cell derived RPE cells can be used in the treatment of AMD (Lee and Maclaren 2011). Use of these cells may be of benefit as they have the potential to replace the lost cells and may not be hindered by the obstacles such as poor adhesion faced with cadaveric or donor derived RPE cells. For dry AMD, cell transplantation strategies are also undergoing clinical trials in several centres worldwide. Strategies to compare improve the survival and adhesion of transplanted cells to damaged Bruch's membrane are a key focus of our ongoing work.

Manipulation of integrins on RPE cells or genetic engineering of transplanted cells is a new field that holds promise in overcoming the obstacles faced in cell transplantation. Activating integrins by enhancing their function or introduction of new subunits of integrins into RPE cells have been shown to overcome the poor attachment and integration of RPE cells over Bruch's membrane (Afshari et al 2010; Fang et al 2009). It is therefore possible that with better understanding of RPE biology, adhesion and survival of cells following transplantation could be improved.

With the advent of the new therapies such as monoclonal anti-VEGF treatments, major advances have occurred in the treatment of wet AMD. At this point the challenges reside in wide access and affordable costs to allow early recognition and prevention of loss of vision at an early stage. Currently repeated injections of monoclonal antibodies limit their use in areas where access to such therapies is limited. With better understanding and experience of using such therapies, it is hoped that treatments with longer half lives and more affordable prices can be available to increasing aging population.

\section{References}

Afshari FT, Kwok JC, Andrews MR, Blits B, Martin KR, Faissner A, Ffrench-Constant C, Fawcett JW. Integrin activation or alpha 9 expression allows retinal pigmented epithelial cell adhesion on Bruch's membrane in wet age-related macular degeneration. Brain. 2010 Feb;133(Pt 2):448-64. 
Age related eye disease study research group (2001). A randomized, placebocontrolled, clinical trial of high-dose supplementation with vitamins $\mathrm{C}$ and $\mathrm{E}$, beta carotene, and zinc for age-related macular degeneration and vision loss: AREDS report no. 8. Arch Ophthalmol 119, 1417-1436.

Algvere, P.V., Berglin, L., Gouras, P., and Sheng, Y. (1994). Transplantation of fetal retinal pigment epithelium in age-related macular degeneration with subfoveal neovascularization. Graefes Arch Clin Exp Ophthalmol 232, 707-716.

Ambati J, Anand A, Fernandez S, Sakurai E, Lynn BC, Kuziel WA, Rollins BJ, Ambati BK. An animal model of age-related macular degeneration in senescent Ccl-2- or Ccr-2deficient mice. Nat Med. 2003 Nov;9(11):1390-7.

Avery RL, Pieramici DJ, Rabena MD, Castellarin AA, Nasir MA, Giust MJ. Intravitreal bevacizumab (Avastin) for neovascular age-related macular degeneration. Ophthalmology. 2006 Mar;113(3):363-372.e5.

Baba T, Bhutto IA, Merges C, Grebe R, Emmert D, McLeod DS, Armstrong D, Lutty GA. A rat model for choroidal neovascularization using subretinal lipid hydroperoxide injection. Am J Pathol. 2010 Jun;176(6):3085-97.

Binder, S., Krebs, I., Hilgers, R.D., Abri, A., Stolba, U., Assadoulina, A., Kellner, L., Stanzel, B.V., Jahn, C., and Feichtinger, H. (2004). Outcome of transplantation of autologous retinal pigment epithelium in age-related macular degeneration: a prospective trial. Invest Ophthalmol Vis Sci 45, 4151-4160.

Bird, A.C., Bressler, N.M., Bressler, S.B., Chisholm, I.H., Coscas, G., Davis, M.D.,de Jong, P.T., Klaver, C.C., Klein, B.E., Klein, R., and et al. (1995). An international classification and grading system for age-related maculopathy and age-related macular degeneration. The International ARM Epidemiological Study Group. Surv Ophthalmol 39, 367-374.

Boulton, M., Dontsov, A., Jarvis-Evans, J., Ostrovsky, M., and Svistunenko, D. (1993). Lipofuscin is a photoinducible free radical generator. J Photochem Photobiol B 19, 201-204.

Bressler, N.M., Silva, J.C., Bressler, S.B., Fine, S.L., and Green, W.R. (1994).Clinicopathologic correlation of drusen and retinal pigment epithelial abnormalities in age-related macular degeneration. Retina 14, 130-142.

Buch H, Vinding T, la Cour M, Jensen GB, Prause JU, Nielsen NV. Risk factors for agerelated maculopathy in a 14-year follow-up study: the Copenhagen City Eye Study. Acta Ophthalmol Scand. 2005 Aug;83(4):409-18.

Cai, H., and Del Priore, L.V. (2006). Gene expression profile of cultured adult compared to immortalized human RPE. Mol Vis 12, 1-14.

Cao J, Zhao L, Li Y, Liu Y, Xiao W, Song Y, Luo L, Huang D, Yancopoulos GD, Wiegand SJ, Wen R. A subretinal matrigel rat choroidal neovascularization (CNV) model and inhibition of $\mathrm{CNV}$ and associated inflammation and fibrosis by VEGF trap.Invest Ophthalmol Vis Sci. 2010 Nov;51(11):6009-17.

Castillo, B.V., Jr., del Cerro, M., White, R.M., Cox, C., Wyatt, J., Nadiga, G., and del Cerro, C. (1997). Efficacy of nonfetal human RPE for photoreceptor rescue: a study in dystrophic RCS rats. Exp Neurol 146, 1-9.

Chakravarthy U, Wong TY, Fletcher A, Piault E, Evans C, Zlateva G, Buggage R, Pleil A, Mitchell $\mathrm{P}$. Clinical risk factors for age-related macular degeneration: a systematic review and meta-analysis. BMC Ophthalmol. 2010 Dec 13;10:31. 
Chang, Y., and Finnemann, S.C. (2007). Tetraspanin CD81 is required for the alpha v beta5integrin-dependent particle-binding step of RPE phagocytosis. J Cell Sci 120, 30533063.

Cui JZ, Kimura H, Spee C, Thumann G, Hinton DR, Ryan SJ. Natural history of choroidal neovascularization induced by vascular endothelial growth factor in the primate. Graefes Arch Clin Exp Ophthalmol. 2000 Apr;238(4):326-33.

Das, A., Frank, R.N., Zhang, N.L., and Turczyn, T.J. (1990). Ultrastructural localization of extracellular matrix components in human retinal vessels and Bruch's membrane. Arch Ophthalmol 108, 421-429.

De La Paz, M., and Anderson, R.E. (1992). Region and age-dependent variation in susceptibility of the human retina to lipid peroxidation. Invest Ophthalmol Vis Sci 33, 3497-3499.

Del Priore, L.V., and Tezel, T.H. (1998). Reattachment rate of human retinal pigment epithelium to layers of human Bruch's membrane. Arch Ophthalmol 116, 335-341

Dobi ET, Puliafito CA, Destro M. A new model of experimental choroidal neovascularization in the rat. Arch Ophthalmol. 1989 Feb;107(2):264-9.

Edwards AO, Malek G. Molecular genetics of AMD and current animal models. Angiogenesis. 2007;10(2):119-32.

Emerson MV, Lauer AK, Flaxel CJ, Wilson DJ, Francis PJ, Stout JT, Emerson GG, Schlesinger TK, Nolte SK, Klein ML. Intravitreal bevacizumab (Avastin) treatment of neovascular age-related macular degeneration.Retina. 2007 Apr-May;27(4):439-44.

Falkner-Radler CI, Krebs I, Glittenberg C, Povazay B, Drexler W, Graf A, Binder S. Human retinal pigment epithelium (RPE) transplantation: outcome after autologous RPEchoroid sheet and RPE cell-suspension in a randomised clinical study. $\mathrm{Br} \mathrm{J}$ Ophthalmol. 2011 Mar;95(3):370-5.

Fang, I.M., Yang, C.H., Yang, C.M., and Chen, M.S. (2008). Overexpression of integrin alpha(6) and beta(4) enhances adhesion and proliferation of human retinal pigment epithelial cells on layers of porcine Bruch's membrane. Exp Eye Res. 2009 Jan;88(1):12-21.

Fasler-Kan, E., Wunderlich, K., Hildebrand, P., Flammer, J., and Meyer, P. (2005). Activated STAT 3 in choroidal neovascular membranes of patients with agerelated macular degeneration. Ophthalmologica 219, 214-221.

Feeney-Burns, L., Hilderbrand, E.S., and Eldridge, S. (1984). Aging human RPE: morphometric analysis of macular, equatorial, and peripheral cells. Invest Ophthalmol Vis Sci 25, 195-200.

Fine, A.M., Elman, M.J., Ebert, J.E., Prestia, P.A., Starr, J.S., and Fine, S.L. (1986). Earliest symptoms caused by neovascular membranes in the macula.Arch Ophthalmol 104, 513-514.

Finnemann, S.C., and Silverstein, R.L. (2001). Differential roles of CD36 and alphavbeta5 integrin in photoreceptor phagocytosis by the retinal pigment epithelium. J Exp Med 194, 1289-1298.

Frank RN, Das A, Weber ML. Curr Eye Res. A model of subretinal neovascularization in the pigmented rat. 1989 Mar;8(3):239-47.

Friedman, D.S., O'Colmain, B.J., Munoz, B., Tomany, S.C., McCarty, C., de Jong, P.T., Nemesure, B., Mitchell, P., and Kempen, J. (2004). Prevalence of agerelated macular degeneration in the United States. Arch Ophthalmol 122, 564-572. 
Goody RJ, Hu W, Shafiee A, Struharik M, Bartels S, López FJ, Lawrence MS. Optimization of laser-induced choroidal neovascularization in African green monkeys. Exp Eye Res. 2011 Jun;92(6):464-72.

Green, W.R., and Enger, C. (2005). Age-related macular degeneration histopathologic studies: the 1992 Lorenz E. Zimmerman Lecture. 1992. Retina 25, 1519-1535.

Grossniklaus, H.E., Hutchinson, A.K., Capone, A., Jr., Woolfson, J., and Lambert, H.M. (1994). Clinicopathologic features of surgically excised choroidal neovascular membranes. Ophthalmology 101, 1099-1111.

Hageman, G.S., Mullins, R.F., Russell, S.R., Johnson, L.V., and Anderson, D.H. (1999). Vitronectin is a constituent of ocular drusen and the vitronectin gene is expressed in human retinal pigmented epithelial cells. FASEB J 13, 477-484.

Hanahan, D. (1997). Signaling vascular morphogenesis and maintenance. Science 277, 48-50.

Hassell JB, Lamoureux EL, Keeffe JE. Impact of age related macular degeneration on quality of life. Br J Ophthalmol. 2006 May;90(5):593-6.

Hewitt, A.T., Nakazawa, K., and Newsome, D.A. (1989). Analysis of newly synthesized Bruch's membrane proteoglycans. Invest Ophthalmol Vis Sci 30,478-486.

Ho, T.C., and Del Priore, L.V. (1997). Reattachment of cultured human retinal pigment epithelium to extracellular matrix and human Bruch's membrane. Invest Ophthalmol Vis Sci 38, 1110-1118.

Hua J, Spee C, Kase S, Rennel ES, Magnussen AL, Qiu Y, Varey A, Dhayade S, Churchill AJ, Harper SJ, Bates DO, Hinton DR. Recombinant human VEGF165b inhibits experimental choroidal neovascularization. Invest Ophthalmol Vis Sci. 2010 Aug;51(8):4282-8.

Ishibashi, T., Miki, K., Sorgente, N., Patterson, R., and Ryan, S.J. (1985). Effects of intravitreal administration of steroids on experimental subretinal neovascularization in the subhuman primate. Arch Ophthalmol 103, 708-711.

Ishibashi, T., Patterson, R., Ohnishi, Y., Inomata, H., and Ryan, S.J. (1986). Formation of drusen in the human eye. Am J Ophthalmol 101, 342-353.

Jager, R.D., Mieler, W.F., and Miller, J.W. (2008). Age-related macular degeneration. N Engl J Med 358, 2606-2617.

Johnson, L.V., Ozaki, S., Staples, M.K., Erickson, P.A., and Anderson, D.H. (2000). A potential role for immune complex pathogenesis in drusen formation. Exp Eye Res 70, 441-449.

Julien S, Kreppel F, Beck S, Heiduschka P, Brito V, Schnichels S, Kochanek S, Schraermeyer U. A reproducible and quantifiable model of choroidal neovascularization induced by VEGF A165 after subretinal adenoviral gene transfer in the rabbit. Mol Vis. 2008 Jul 30;14:1358-72.

Katz, M.L., Christianson, J.S., Gao, C.L., and Handelman, G.J. (1994). Iron induced fluorescence in the retina: dependence on vitamin A. Invest Ophthalmol Vis Sci 35, 3613-3624.

Killingsworth, M.C. (1987). Age-related components of Bruch's membrane in the human eye. Graefes Arch Clin Exp Ophthalmol 225, 406-412.

Kim, I., Ryan, A.M., Rohan, R., Amano, S., Agular, S., Miller, J.W., and Adamis,A.P. (1999). Constitutive expression of VEGF, VEGFR-1, and VEGFR-2 in normal eyes. Invest Ophthalmol Vis Sci 40, 2115-2121. 
King, G.L., and Brownlee, M. (1996). The cellular and molecular mechanisms of diabetic complications. Endocrinol Metab Clin North Am 25, 255-270.

Klein, R.J., Zeiss, C., Chew, E.Y., Tsai, J.Y., Sackler, R.S., Haynes, C., Henning, A.K., SanGiovanni, J.P., Mane, S.M., Mayne, S.T., et al. (2005). Complement factor H polymorphism in age-related macular degeneration. Science 308, 385-389.

Kliffen, M., Sharma, H.S., Mooy, C.M., Kerkvliet, S., and de Jong, P.T. (1997). Increased expression of angiogenic growth factors in age-related maculopathy. $\mathrm{Br} \mathrm{J}$ Ophthalmol 81, 154-162.

Krzystolik, M.G., Afshari, M.A., Adamis, A.P., Gaudreault, J., Gragoudas, E.S., Michaud, N.A., Li, W., Connolly, E., O'Neill, C.A., and Miller, J.W. (2002). Prevention of experimental choroidal neovascularization with intravitreal antivascular endothelial growth factor antibody fragment. Arch Ophthalmol 120,338-346.

Kvanta, A., Algvere, P.V., Berglin, L., and Seregard, S. (1996). Subfoveal fibrovascular membranes in age-related macular degeneration express vascular endothelial growth factor. Invest Ophthalmol Vis Sci 37, 1929-1934.

Lassota N. Clinical and histological aspects of CNV formation: studies in an animal model. Acta Ophthalmol. 2008 Sep;86 Thesis 2:1-24.

Lee E, Maclaren RE. Sources of retinal pigment epithelium (RPE) for replacement therapy. Br J Ophthalmol. 2011 Apr;95(4):445-9.

Li, L.X., and Turner, J.E. (1988a). Inherited retinal dystrophy in the RCS rat: prevention of photoreceptor degeneration by pigment epithelial cell transplantation. Exp Eye Res 47, 911-917. 313

Li, L.X., and Turner, J.E. (1988b). Transplantation of retinal pigment epithelial cells to immature and adult rat hosts: short- and long-term survival characteristics. Exp Eye Res 47, 771-785.

Lu, M., Kuroki, M., Amano, S., Tolentino, M., Keough, K., Kim, I., Bucala, R.,and Adamis, A.P. (1998). Advanced glycation end products increase retinal vascular endothelial growth factor expression. J Clin Invest 101, 1219-1224.

Lund, R.D., Kwan, A.S., Keegan, D.J., Sauve, Y., Coffey, P.J., and Lawrence, J.M. (2001). Cell transplantation as a treatment for retinal disease. Prog Retin Eye Res 20, 415-449

Lyzogubov VV, Tytarenko RG, Liu J, Bora NS, Bora PS. Polyethylene glycol (PEG)-induced mouse model of choroidal neovascularization. J Biol Chem. 2011 May 6;286(18):16229-37.

MacLaren, R.E., Uppal, G.S., Balaggan, K.S., Tufail, A., Munro, P.M., Milliken, A.B., Ali, R.R., Rubin, G.S., Aylward, G.W., and da Cruz, L. (2007).

Maisonpierre, P.C., Suri, C., Jones, P.F., Bartunkova, S., Wiegand, S.J., Radziejewski, C., Compton, D., McClain, J., Aldrich, T.H., Papadopoulos, N.,et al. (1997). Angiopoietin-2, a natural antagonist for Tie2 that disrupts in vivo angiogenesis. Science 277, 55-60.

Maseruka, H., Bonshek, R.E., and Tullo, A.B. (1997). Tenascin-C expression in normal, inflamed, and scarred human corneas. Br J Ophthalmol 81, 677-682.

Mitchell P. A systematic review of the efficacy and safety outcomes of anti-VEGF agents used for treating neovascular age-related macular degeneration: comparison of ranibizumab and bevacizumab. Curr Med Res Opin. 2011 Jul;27(7):1465-75.

Montezuma SR, Vavvas D, Miller JW. Review of the ocular angiogenesis animal models. Semin Ophthalmol. 2009 Mar-Apr;24(2):52-61. 
Mousa, S.A., Lorelli, W., and Campochiaro, P.A. (1999). Role of hypoxia and extracellular matrix-integrin binding in the modulation of angiogenic growth factors secretion by retinal pigmented epithelial cells. J Cell Biochem 74, 135-143.

Mullins, R.F., Russell, S.R., Anderson, D.H., and Hageman, G.S. (2000). Drusen associated with aging and age-related macular degeneration contain proteins common to extracellular deposits associated with atherosclerosis, elastosis, amyloidosis, and dense deposit disease. FASEB J 14, 835-846.

Nandrot, E.F., Kim, Y., Brodie, S.E., Huang, X., Sheppard, D., and Finnemann, S.C. (2004). Loss of synchronized retinal phagocytosis and age-related blindness in mice lacking alphavbeta5 integrin. J Exp Med 200, 1539-1545.

Nicolo, M., Piccolino, F.C., Zardi, L., Giovannini, A., and Mariotti, C. (2000). Detection of tenascin-C in surgically excised choroidal neovascular membranes. Graefes Arch Clin Exp Ophthalmol 238, 107-111.

Okamoto N, Tobe T, Hackett SF, Ozaki H, Vinores MA, LaRochelle W, Zack DJ, Campochiaro PA. Transgenic mice with increased expression of vascular endothelial growth factor in the retina: a new model of intraretinal and subretinal neovascularization. Am J Pathol. 1997 Jul;151(1):281-91.

Pauleikhoff, D., Harper, C.A., Marshall, J., and Bird, A.C. (1990). Aging changes in Bruch's membrane. A histochemical and morphologic study. Ophthalmology 97, 171-178.

Pauleikhoff, D., Spital, G., Radermacher, M., Brumm, G.A., Lommatzsch, A., and Bird, A.C. (1999). A fluorescein and indocyanine green angiographic study of choriocapillaris in age-related macular disease. Arch Ophthalmol 117, 1353-1358.

Phillips, S.J., Sadda, S.R., Tso, M.O., Humayan, M.S., de Juan, E., Jr., and Binder,S. (2003). Autologous transplantation of retinal pigment epithelium after mechanical debridement of Bruch's membrane. Curr Eye Res 26, 81-88.

Piermarocchi S, Varano M, Parravano M, Oddone F, Sartore M, Ferrara R, Sera F, Virgili G. Quality of Vision Index: a new method to appraise visual function changes in agerelated macular degeneration. Eur J Ophthalmol. 2011 Jan-Feb;21(1):55-66.

Ramrattan, R.S., van der Schaft, T.L., Mooy, C.M., de Bruijn, W.C., Mulder, P.G., and de Jong, P.T. (1994). Morphometric analysis of Bruch's membrane, the choriocapillaris, and the choroid in aging. Invest Ophthalmol Vis Sci 35, 2857-2864.

Remulla, J.F., Gaudio, A.R., Miller, S., and Sandberg, M.A. (1995). Foveal electroretinograms and choroidal perfusion characteristics in fellow eyes of patients with unilateral neovascular age-related macular degeneration. Br J Ophthalmol 79, 558-561.

Rikans, L.E., and Moore, D.R. (1988). Effect of aging on aqueous-phase antioxidants in tissues of male Fischer rats. Biochim Biophys Acta 966, 269-275.

Rivera, A., Fisher, S.A., Fritsche, L.G., Keilhauer, C.N., Lichtner, P., Meitinger, T., and Weber, B.H. (2005). Hypothetical LOC387715 is a second major susceptibility gene for age-related macular degeneration, contributing independently of complement factor $\mathrm{H}$ to disease risk. Hum Mol Genet 14,3227-3236.

Ryan SJ. The development of an experimental model of subretinal neovascularization in disciform macular degeneration. Trans Am Ophthalmol Soc. 1979;77:707-45.

Saishin Y, Saishin Y, Takahashi K, Lima e Silva R, Hylton D, Rudge JS, Wiegand SJ, Campochiaro PA. VEGF-TRAP(R1R2) suppresses choroidal neovascularization and VEGF-induced breakdown of the blood-retinal barrier. J Cell Physiol. 2003 May;195(2):241-8. 
Sakaguchi, H., Miyagi, M., Shadrach, K.G., Rayborn, M.E., Crabb, J.W., and Hollyfield, J.G. (2002). Clusterin is present in drusen in age-related macular degeneration. Exp Eye Res 74, 547-549.

Sallo FB, Peto T, Leung I, Xing W, Bunce C, Bird AC. The International Classification system and the progression of age-related macular degeneration. Curr Eye Res. 2009 Mar;34(3):238-40.

Schmidt, A.M., Yan, S.D., Yan, S.F., and Stern, D.M. (2000). The biology of the receptor for advanced glycation end products and its ligands. Biochim Biophys Acta 1498, 99111.

Schmidt, S., Hauser, M.A., Scott, W.K., Postel, E.A., Agarwal, A., Gallins, P.,Wong, F., Chen, Y.S., Spencer, K., Schnetz-Boutaud, N., et al. (2006). Cigarette smoking strongly modifies the association of LOC387715 and age related macular degeneration. Am J Hum Genet 78, 852-864.

Schmidt-Erfurth UM, Elsner H, Terai N, Benecke A, Dahmen G, Michels SM. Effects of verteporfin therapy on central visual field function. Ophthalmology. 2004 May;111(5):931-9.

Schwesinger, C., Yee, C., Rohan, R.M., Joussen, A.M., Fernandez, A., Meyer, T.N., Poulaki, V., Ma, J.J., Redmond, T.M., Liu, S., et al. (2001). Intrachoroidal neovascularization in transgenic mice overexpressing vascular endothelial growth factor in the retinal pigment epithelium. Am J Pathol 158, 1161-1172.

Spilsbury K, Garrett KL, Shen WY, Constable IJ, Rakoczy PE. Overexpression of vascular endothelial growth factor (VEGF) in the retinal pigment epithelium leads to the development of choroidal neovascularization. Am J Pathol. 2000 Jul;157(1):135-44.

Starita, C., Hussain, A.A., Patmore, A., and Marshall, J. (1997). Localization of the site of major resistance to fluid transport in Bruch's membrane. Invest Ophthalmol Vis Sci 38, 762-767.

Sun, K., Cai, H., Tezel, T.H., Paik, D., Gaillard, E.R., and Del Priore, L.V. (2007). Bruch's membrane aging decreases phagocytosis of outer segments by retinal pigment epithelium. Mol Vis 13, 2310-2319.

Sundelin, S.P., and Nilsson, S.E. (2001). Lipofuscin-formation in retinal pigment epithelial cells is reduced by antioxidants. Free Radic Biol Med 31, 217-225.

Tanaka N, Ikawa M, Mata NL, Verma IM. Choroidal neovascularization in transgenic mice expressing prokineticin 1: an animal model for age-related macular degeneration. Mol Ther. 2006 Mar;13(3):609-16. Epub 2005 Nov 2.

Treatment of Age-related macular degeneration with Photodynamic therapy (TAP) Study Group. Photodynamic therapy of subfoveal choroidal neovascularization in agerelated macular degeneration with verteporfin: one-year results of 2 randomized clinical trials--TAP report. Archives of Ophthalmology 1999;117(10):1329-45.

Tezel, T.H., and Del Priore, L.V. (1997). Reattachment to a substrate prevents apoptosis of human retinal pigment epithelium. Graefes Arch Clin Exp Ophthalmol 235, 41-47.

Tezel, T.H., and Del Priore, L.V. (1999). Repopulation of different layers of host human Bruch's membrane by retinal pigment epithelial cell grafts. Invest Ophthalmol Vis Sci 40, 767-774.

Tezel, T.H., Kaplan, H.J., and Del Priore, L.V. (1999). Fate of human retinal pigment epithelial cells seeded onto layers of human Bruch's membrane. Invest Ophthalmol Vis Sci 40, 467-476 
Treumer F, Bunse A, Klatt C, Roider J. Autologous retinal pigment epithelium-choroid sheet transplantation in age related macular degeneration: morphological and functional results.Br J Ophthalmol. 2007 Mar;91(3):349-53.

Tsukahara, I., Ninomiya, S., Castellarin, A., Yagi, F., Sugino, I.K., and Zarbin, M.A. (2002). Early attachment of uncultured retinal pigment epithelium from aged donors onto Bruch's membrane explants. Exp Eye Res 74, 255-266.

Vandewoude, M.F., and Vandewoude, M.G. (1987). Vitamin E status in a normal population: the influence of age. J Am Coll Nutr 6, 307-311.

Vedula S.S, Krzystolik M.G.(2008). Antiangiogenic therapy with anti-vascular endothelial growth factor modalities for neovascular age-related macular degeneration. Cochrane Database Syst Rev. 2008 Apr 16;(2):CD005139.

Virgili G, Bini A. Laser photocoagulation for neovascular agerelated macular degeneration. Cochrane Database of Systematic Reviews 2007, Issue 3.

Wallace, D.C., Brown, M.D., Melov, S., Graham, B., and Lott, M. (1998). Mitochondrial biology, degenerative diseases and aging. Biofactors 7, 187-190.

Wallace, D.C. (1999). Mitochondrial diseases in man and mouse. Science 283, 1482-1488. Harman, D. (1956). Aging: a theory based on free radical and radiation chemistry. J Gerontol 11, 298-300.

Wang, S., Lu, B., Wood, P., and Lund, R.D. (2005). Grafting of ARPE-19 and Schwann cells to the subretinal space in RCS rats. Invest Ophthalmol Vis Sci 46, 2552-2560.

Wassell, J., Davies, S., Bardsley, W., and Boulton, M. (1999). The photoreactivity of the retinal age pigment lipofuscin. J Biol Chem 274, 23828-23832.

Winkler, B.S., Boulton, M.E., Gottsch, J.D., and Sternberg, P. (1999). Oxidative damage and age-related macular degeneration. Mol Vis 5, 32.

Wong TY, Hyman L. Population-based studies in ophthalmology. Am J Ophthalmol. 2008 Nov;146(5):656-63.

Zagzag, D., and Capo, V. (2002). Angiogenesis in the central nervous system: a role for vascular endothelial growth factor/vascular permeability factor and tenascin-C. Common molecular effectors in cerebral neoplastic and nonneoplastic "angiogenic diseases". Histol Histopathol 17, 301-321.

Zagzag, D., Friedlander, D.R., Dosik, J., Chikramane, S., Chan, W., Greco, M.A.,Allen, J.C., Dorovini-Zis, K., and Grumet, M. (1996). Tenascin-C expression by angiogenic vessels in human astrocytomas and by human brain endothelial cells in vitro. Cancer Res 56, 182-189.

Zarbin, M.A. (2003). Analysis of retinal pigment epithelium integrin expression and adhesion to aged submacular human Bruch's membrane. Trans Am Ophthalmol Soc 101, 499-520.

Zarbin, M.A. (2004). Current concepts in the pathogenesis of age-related macular degeneration. Arch Ophthalmol 122, 598-614. 


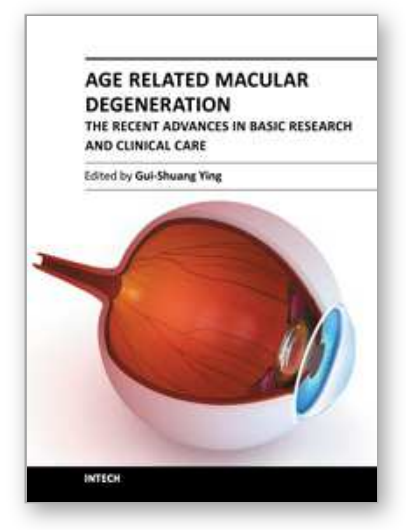

\author{
Age Related Macular Degeneration - The Recent Advances in Basic \\ Research and Clinical Care \\ Edited by Dr. Gui-Shuang Ying
}

ISBN 978-953-307-864-9

Hard cover, 300 pages

Publisher InTech

Published online 20, January, 2012

Published in print edition January, 2012

Age-related Macular Degeneration (AMD) is the leading cause of vision loss and blindness in the developed countries. In the past decade, great progress has been made in understanding the pathobiology and genetics of this blinding disease, as well as in finding new therapies for its treatment. These include the discovery of several genes that are associated with the risk of AMD, new anti-VEGF treatments for wet AMD and new imaging techniques to diagnose and monitor the AMD. All chapters in this book were contributed by outstanding research scientists and clinicians in the area of AMD. I hope this timely book will provide the basic scientists and clinicians with an opportunity to learn about the recent advances in the field of AMD.

\title{
How to reference
}

In order to correctly reference this scholarly work, feel free to copy and paste the following:

Fardad Afshari, Chris Jacobs, James Fawcett and Keith Martin (2012). Wet Age Related Macular Degeneration, Age Related Macular Degeneration - The Recent Advances in Basic Research and Clinical Care, Dr. Gui-Shuang Ying (Ed.), ISBN: 978-953-307-864-9, InTech, Available from:

http://www.intechopen.com/books/age-related-macular-degeneration-the-recent-advances-in-basic-researchand-clinical-care/wet-amd

\section{INTECH}

open science | open minds

\author{
InTech Europe \\ University Campus STeP Ri \\ Slavka Krautzeka 83/A \\ 51000 Rijeka, Croatia \\ Phone: +385 (51) 770447 \\ Fax: +385 (51) 686166 \\ www.intechopen.com
}

\author{
InTech China \\ Unit 405, Office Block, Hotel Equatorial Shanghai \\ No.65, Yan An Road (West), Shanghai, 200040, China \\ 中国上海市延安西路65号上海国际贵都大饭店办公楼405单元 \\ Phone: +86-21-62489820 \\ Fax: +86-21-62489821
}


(C) 2012 The Author(s). Licensee IntechOpen. This is an open access article distributed under the terms of the Creative Commons Attribution 3.0 License, which permits unrestricted use, distribution, and reproduction in any medium, provided the original work is properly cited. 